\title{
Reflections: testifying in the Minnesota tobacco lawsuit
}

"You may stand down." I hear these words on Friday, 13 February 1998 in the federal courthouse in Minnesota after two and one-half days on the stand as a witness for the plaintiffs in the lawsuit filed by the state of Minnesota and Blue Cross/Blue Shield of Minnesota against the tobacco manufacturers. Three months later, on 8 May 1998, I learn that there has been a massive settlement that brings US $\$ 6.5$ billion to the plaintiffs and concessions to public health that will long reverberate. With this landmark trial completed, I am writing to describe my experience as an expert, covering my decision to participate, the preparatory work for the trial, and the presentation of testimony in the courtroom.

My decision to participate in the trial was made deliberately and slowly. I was approached in mid-1994 and asked to consider working with the plaintiffs' counsel, the firm of Robins, Kaplan, Miller \& Ciresi in Minneapolis. Legal actions against the tobacco industry were not front page and daily news at the time and I took some months to puzzle through the basis of the lawsuits, their legitimacy, and the motivations and qualifications of the various players in the Minnesota case. Conversations with knowledgeable friends provided assurance, and further contact with the plaintiffs' attorneys convinced me that their motivations were sincere and that the public health community had new allies - attorneys - in the struggle against the tobacco industry, I came to view the lawsuits as a public health initiative. Even though I had eschewed the role of expert witness, I knew that I did not want to miss the opportunity to contribute to a potentially historic legal action. Other decisions needed to be faced: should I accept personally the expert fees that would mount over the next few years? How would I add work on the case to an already frenetic schedule? The first question was quickly answered, as I continued my personal policy of not accepting the fees myself, but instead donated them to my department. The work of trial preparation was largely accomplished during evenings and weekends, the attorneys being accommodating to my schedule. In fact, as the trial date approached in late 1997 and early 1998, few weekends did not involve preparation for the trial. I was further assisted during the trial preparation by the work of an epidemiologist, Tracy Sides, who helped me to develop a database of evidence on the findings of epidemiological studies on tobacco smoking.
In accepting, I had little understanding of the scope of the work to be done. Over the three years beginning in 1995 and ending with my testimony, we assembled a standardised database with the findings of over $900 \mathrm{key}$ epidemiological reports, refined the models used to estimate the health costs of smoking, and prepared the trial exhibits. I authored an expert report, gave depositions for two days and testimony for nearly three days. I now understand the flow and rhythm of being an expert, with its peaks of intensity as reports are written, and preparations are made for depositions or testimony. The urgency of these moments is engrossing, requiring maintained focus and commitment.

Contact with the defense attorneys first occurs with the deposition, an interrogation that has the purpose of revealing to the other side what the expert will say in court. The goal of the witness, from my lay perspective, seems to be completing the deposition without making statements that may impugn the overall thrust of the case or future testimony. I was prepared with general principles: "Do not volunteer"; "Ask for the question to be repeated"; and "Do not answer questions that cannot be answered". Carefully prepared, I was ready for my two days of deposition in mid-summer of 1997.

As the date for my mandated two days approaches, strategic games by the other side become evident. There are requests for postponement of my deposition and outraged requests for more time to review the database of epidemiologic evidence, which had been provided but apparently not viewed in a timely fashion by the defense team. The attorneys offer arguments and finally the scheduling of my deposition rests with the judge. A decision is made within the hour that I need to leave for the airport, splitting my deposition across two days, one in July and the other in the fall.

During the deposition's first hours, I quickly learn that the process is unpleasant and antithetical to my scientific principles, but survivable without loss of credibility. The attorneys ask about epidemiology and the findings of epidemiologic studies; they quiz me about principles that would be known to any graduate student in a seeming attempt to intimidate with their knowledge. My responses quiet them, as the limits of their understanding are exceeded. After all, they are only lawyers. Many questions are posed as long, often disjointed hypothetical statements, ending or 
beginning with "Wouldn't you agree doctor that ..."

In late fall 1997, intensity mounts as the trial date approaches, a seeming reality. Now, we face the challenge of preparing trial exhibits. How does one educate a lay jury about epidemiology? Tell the jury about the mechanisms by which smoking causes disease? Present 50 years of epidemiologic findings? Fortunately, I learn that there are experts in the presentation of information to juries and I work for several months with a firm, Z-Axis, in preparing the exhibits. Some of the presentation material is straightforward-design principles for various types of epidemiologic studies and the design of such key investigations as the Framingham and British doctors studies, for example. The innovative approach of animation solves the presentation of 50 years of data. For lung cancer and other key diseases, a three-dimensional animation shows the dramatic march of relative risk values from individual studies from 1950 through the present. Skyscraper-like columns rise well beyond the marked reference point, a relative risk of unity. The number of columns and their height impress the observer.

Christmas holidays in January are spent in preparing testimony, covering the questions that I will be asked and the exhibits that I will use in response. The plan is much like a play with acts: my qualifications, an introduction to epidemiology, an overview of how smoking causes disease, the evidence on individual diseases, and finally, the denouement, the link between health effects of smoking and costs. Practice follows up to the moment of the testimony.

The trial is slated to begin on 20 January 1998 with jury selection. Drama surrounds the trial's opening: will there be a settlement? Will the attorney general, Hubert Humphrey III, abandon his skeptical stance against settlement if enough dollars are offered and concessions to public health demands are made? With prior settlements in Mississippi, Florida, and Texas, there seems to be a real possibility that the trial will not take place; I realise that I will be disappointed if the trial does not proceed.

However, the trial begins and jury selection proceeds quickly. I read transcripts of my predecessors on the witness stand with interest-Richard Hurt from the Mayo Clinic, who addresses nicotine addiction and Channing Robertson from Stanford University, who addresses the design of cigarettes. Immediately before me, the plaintiffs have called Walker Merryman, the long-term spokesman for the Tobacco Institute. I travel to St Paul, awaiting further completion of Merryman's cross-examination and testimony. In the meantime, preparation continues, occupying at least 16 hours daily. My world is limited to the 11 th floor of the St Paul Hotel, transformed into an office, document depository, and dormitory. An off-duty policeman guards the entrance to the floor and sweepers for electronic "bugs" periodically pass through. I go to the courtroom to familiarise myself with the scene and its feel. I watch as Walker Merryman denies any connection between cigarette smoking and disease, stating that this is the policy of the Tobacco Institute. I sense that the truth will look better than hollow denials.

Finally, mid-week, on Wednesday afternoon, 11 February, my testimony begins. The 12 jurors are to my left and the judge and court reporters to my right. One table is occupied by the attorneys from Robins, Kaplan, Miller \& Ciresi, while two are needed to accommodate those from the other side. Tom Hamlin, who will question me, is a familiar and friendly face. Exhibits and evidence are stacked in front of me, as are notebooks of documents and exhibits. I have a touch screen for running the animations.

The first half-day passes quickly. I am introduced and my professional qualifications reviewed with embarrassing grandiosity and in excruciating detail. I find that an accounting of my professional life is boring me and wonder how others, including the jury, could possibly be interested in my professional genealogy and seemingly endless scholarly works and professional societies. But this accounting of my personal history offers time to sense the play of the courtroom and to occasionally look at the jurors. At mid-afternoon, Judge Fitzpatrick cautions both sides for their behavior: Tom Hamlin for leaning against the jury box, a posture that seemed standard in legal dramas, and the defense for aggressively and noisily shuffling papers. That behavior had occurred episodically and seemed intended to distract. The remainder of the session covers the anatomy and functioning of the lung, the characteristics of tobacco smoke and mechanisms of injury by tobacco smoke components, the fundamentals of epidemiologic research, and the determination of causal associations. I end by covering the scientific evidence on smoking and lung cancer. At the last, I make the point that lung cancer is almost invariably fatal and provide a lung specimen infiltrated with cancer for the jury's inspection. As I again speak to the death sentence that lung cancer imposes, a juror silently begins to cry and the judge ends the afternoon's testimony.

Afterwards, we agree that the first half-day has gone well. The presentation materials were successful for teaching the jury and for avoiding tedious pontification by the expert. We have used a three-dimensional model to cover anatomy and physiology, and shown videos of smoke passing through the lung and components entering the circulation. Epidemiologic study designs have been shown on large boards that illustrate design features and findings of classic studies. The animations of the epidemiologic evidence have proved effective as well.

That night, we prepare for the next day and focus with intensity in preparing for my crossexamination which seems likely to happen on the day following. Members of the team play the adversarial role; I treat this with humor, applying epithets to this pretend opposition, but I recognise the serious intent of the exercise. I stumble in answering some of the difficult questions that I may hear from the defense. 
The next full day is taken up by testimony on the remaining diseases caused by smoking, the consequences of changes in the cigarette over time, and the ways that clinical encounters for disease are coded. All sense that a key part of the story is being laid out: smoking causes disease, the care of disease costs money, and we have a coding system that is used to identify which diseases have necessitated clinical care.

By now, I have become comfortable on the witness stand and have an understanding of the landscape at my sides and in front of me. The 12 jurors are immediately to my left. They are following every word closely and taking notes. Some look at me intently and return my gaze, while others look away. Some appear friendly and smile, much like students who are learning successfully. I am left curious as to what they are thinking. The judge is to my right, intent and inscrutable. The plaintiffs' attorneys are in front of the witness stand and closest to me. I learn to ignore defense counsel, who appear to be a well-dressed but mean-spirited lot. The public is in the distance, including Tracy Sides, some reporters, and others. Time has expanded to units of around an hour, the interval during which testimony is presented between breaks. I watch the clock and finds that it moves slowly.

With direct testimony over, we again spend the night preparing for cross-examination. We have been given nearly 100 papers and documents that may be brought up during the cross-examination; they have been scoured to identify the potential points of attack and I review them and consider responses. The scope of the evidence on tobacco and disease and the prospect of being asked about any detail leaves me concerned, as does the novelty of the situation that I will face on the next day, having never testified previously. I am given assurance but sleep fitfully.

As we return to the courtroom for my crossexamination, the analogy to battle is made clear by Mike Ciresi who issues a call to arms, much like a general motivating his troops for combat. The feel of the courtroom is now different; Tom Hamlin emphasised my expert status and my testimony told the story of how smoking causes disease. The attorney for the defense has the purpose of threatening my credibility and raising questions in the jurors' minds as to the veracity of my testimony. My mental set changes and I steel myself into calm. The questions begin and I find them to be annoying in their style and intent but readily managed. Defense counsel, although billed as methodologically savvy, cannot rebound from truthful but sophisticated answers that seem to deviate from the copious notes in front of him. $\mathrm{He}$ becomes flustered and even disorganised and asks for a lunch break 45 minutes early; I sense that the cross-examination may end without any serious threat to my testimony but do not flaunt my knowledge.

The substance of the cross-examination covers familiar themes: causality and the philosophical nexus of identifying a cause; the seeming complexity and impossibility of "controlling" for factors other than cigarette smok- ing; and the interpretation of the scientific evidence on smoking over time. These themes are not surprising and merely echo decades of writing by scientists on the smoking-disease link. Joseph Berkson, the esteemed Mayo Clinic statistician, is offered as one of the skeptics. A 1957 publication is offered as showing that the initial cohort study of the American Cancer Society was affected by selection bias. Berkson's explanation is readily shown to be fallacious, as he reached a conclusion concerning possible selection bias on the basis of a comparison of the lung cancer rate in never-smokers in the American Cancer Society cohort with the overall rate for the American population, including, of course, smokers and never-smokers. Dr Berkson's “error" is immediately evident as his statements are presented and I quietly, but triumphantly, indicate that Berkson mistakenly compared these two incompatible rates. I become weary of questions concerning the knowledge of the scientific community in the 1950 s. Certainly, the beliefs of Doll, Wynder, and others were not personally known to me from that time, and I remind the defense counsel that I was entering elementary school in those years. But the questions continue.

Q: And Sir Richard Doll writes the following: 'I think the sceptical reaction of the medical and cancer research scientists was partly because they smoked themselves and partly because they were unaccustomed to the interpretation of epidemiological data and tended to judge causality by Koch's postulates. Advisors to the government were pathologically scared of causing cancer phobia by undertaking any publicity about cancer, even to the extent of opposing education about the need for early diagnosis. Within government there was anxiety about the effects of reduced sales on tax income and there was certainly a desire to work with the industry rather than against it.' Now do you agree that in the 1950s medical and cancer research scientists were unaccustomed to the interpretation of epidemiologic data?

A: I can't speak to that myself. I see what Richard Doll has written to Ernst Wynder.

My testimony ends with a brief period of re-direct from Tom Hamlin and a few final questions from defense counsel. Among the items covered in the re-direct is Dr Berkson's consultant role to the tobacco industry. The day is over and I leave the courtroom, not for celebration, but for a needed opportunity to review the day with my colleagues and to begin to make the needed breaks as our team dissolves after three years of intense work. Over the remainder of the trial, I remain in close touch, monitoring the progress of the trial and offering occasional guidance on specific points.

As the trial draws to a close, I begin to anticipate learning about the jury's decision in some months hence. I assume, but want confirmation, that any jury of Americans will agree that cigarette smoking causes disease. I see the issue of damages as more complex, and involving model-based calculations that might possibly appear too theoretical. Finally, the last 
day of the trial is at hand. Michael Ciresi is to present closing arguments and then the case will go to the jury. On this very morning, I am notified of the settlement between the plaintiffs and the tobacco industry. The terms are very favorable, both with regard to the damages to be paid and the concessions made to public health issues. I reflect briefly on my role and contributions, and feel exultant. At the same time, I am left questioning as to the decision that the jury might have made. I would have liked to see this final test of the evidence on smoking and disease, which has long been incontrovertible to the scientific community but not tested in a trial of this magnitude by a jury's perspective and decision.

Will I testify again? The Minnesota trial will remain a landmark for the rigor of its preparation, the revelations from the millions of documents that were obtained, and for the advancement of approaches to modeling the damages to health from smoking. Other states are suing and other organisations are contemplating lawsuits. Unfortunately, the pool of potential experts is limited and the most knowledgeable should be presenting the evidence on tobacco and disease. I will continue to work in this new partnership between plaintiff's lawyers and the public health community; the stakes are too important not to.

\section{Postscript}

This commentary was originally written and completed in June 1998. A number of colleagues commented, and some advised against publication, cautioning that even these reflections might be used by attorneys defending the tobacco industry. However, with the settlement between the 46 states and the tobacco industry agreed to in late November 1998, I wanted to make sure that my experience in one phase of the legal battle against the tobacco industry was recorded. Since serving as an expert in the Minnesota case, I have also testified in the Engle class action suit in Florida and for the Federal Trade Commission. I remain convinced that public health scientists should participate in these lawsuits as experts.

Department of Epidemiology,

JONATHAN M SAMET

School of Hygiene and Public Health,

fohns Hopkins University,

615 North Wolfe Street, Suite 6041

Baltimore, Maryland 21205, USA,

jsamet@jhsph.edu

Examples from the cross-examination

Q: Dr Samet, can you tell me why the relative risks increased from CPS-I to CPS-II?

Mr Hamlin: Objection, Your Honor, asked and answered.

The court: No, you may answer that.

A: In terms of a specific reason that is testable by comparing the two studies? No.

Q: Thank you. Now this chart does not separate out low tar cigarette smokers from high tar cigarette smokers; correct?

A: That's correct.

Q: And this chart really doesn't tell us whether low tar cigarette smokers have a reduced lung cancer risk as compared with high tar cigarette smokers; correct?

A: Correct.

Q: Okay. And it doesn't tell us the reverse, it doesn't tell us if high tar cigarette smokers have an increased risk - have a-have a lower risk than low tar cigarette smokers; correct?

A: There's no information about tar.

Q: This is what [Dr Shrek] said: "The correlation is definitely statistically significant, but is it biologically significant? A statistical study cannot prove whether there is a cause-andeffect relationship between two factors. At best, the statistical study can provide circumstantial evidence that a correlation is biologically significant." Dr Samet, do you agree that at best the statistical study can provide circumstantial evidence that a correlation is biologically significant?

A: 'I'm sorry, can you repeat the question?'

Q: Is it fair to say that-again prior to the 1964 report - the failure to obtain lung cancers in laboratory animals exposed to whole smoke was one reason why some medical specialists, toxicologists, pathologists, other medical specialists, believed that smoking had not been definitively proven to be a link-to be a cause of lung cancer?

Mr Hamlin: Objection to foundation and form.

The court: No, you may answer that.

The witness: Can you repeat the question? Mr Garnick: Can I have the question read back, please. (Record read by the court reporter)

A: There may have been such writings. Although I-I think, again, the need for animal studies when in fact there's so much human evidence available even through '64 questions that approach to doubting a causal connection. Q: And you're questioning that approach today; correct?

A: Well, with literally millions of people dead up to now from lung cancer who have chosen to smoke, I have no reason to ask for proof from animals.

Q: Doctor, would it be fair to say that in the science of epidemiology-well, strike that. Would it be fair to say that epidemiology does not know whether removal of any of the carcinogens found in tobacco smoke would lead to a cigarette that would be, in your view, safe to human beings?

Mr Hamlin: Objection, outside the scope, Your Honor, once again.

The court: Sustained.

Q: Doctor, have you investigated whether, in the early 1950s, some of Dr Wynder's colleagues failed to acknowledge that Dr Wynder's studies were consistent with biological plausibility?

A: No, not directly.

Q: On page 691 at the bottom, continuing on to page 692, Dr Wynder states, "Perhaps part of the problem early on was that the medical 
profession as well as science writers have had generally a critical view of epidemiology." Doctor, do you know one way or the other whether in the 1950s the medical profession as well as science writers had a critical view of epidemiology?
A: Well speaking-

Mr Hamlin: Objection to foundation.

The court: You may answer if you know.

A: I was just going to point out that I was in elementary school in the 1950s. I can't answer the question. 